\title{
Bioactivity, Biocompatibility and Biomimetic Properties for Dental Materials: Clarifying the Confusion?
}

\author{
Barry M Owens $^{1 *}$ and Jeffrey G Phebus ${ }^{2}$ \\ ${ }^{1}$ DDS, Professor and Interim Chair, Department of Restorative Dentistry, University of Tennessee Health Sciences Center, College of Dentistry, \\ Memphis, TN, USA \\ ${ }^{2}$ DDS, Associate Professor, Department of Endodontics, University of Tennessee Health Sciences Center, College of Dentistry, Memphis, TN, USA
}

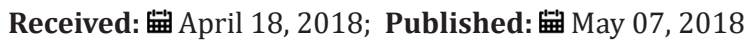

*Corresponding author: Barry M Owens, Interim Chair and Professor, Department of Restorative Dentistry, University of Tennessee,College of Dentistry 875 Union Avenue Memphis, TN 38163, USA

\begin{abstract}
Often in the profession of dentistry, a new or novel instrument, material, technique, and/or "system" is introduced which can incur a "state-of-the-art" status without necessarily being subjected to the rigors of clinical testing or longitudinal patient-based studies prior to receiving the stamp of approval or the moniker of "standard of care". Recently, provocative terminology surrounding the field of dental materials has been publicized through the literature, promoting exciting claims and possible long-term advancements for patient care. In this "new era" of evidence-based restorative dentistry; conservative interdiction, i.e. "informed" removal of diseased tissue with concurrent substitution considering form and function, esthetics, and the interaction of the physical and mechanical properties of the replacement materials with living, dynamic structures found in the human tooth, has been of paramount importance.
\end{abstract}

Abbreviations: ACP: Amorphous Calcium Phosphates; MTA: Mineral Trioxide Aggregate; PVPA: Poly Vinyl Phosponic Acid; PAA: Polyacrylic Acids

\section{Introduction}

The progression or evolution of dentistry has occurred, to a great degree, in concert, with the development of material technology [1]. During the last two decades, the categorization of dental materials, specifically, adhesive systems and composite resins have included the term "nanotechnology" into the lexicon of scientific literature [2]. Nanotechnology involves the science and engineering of functional molecules at the nanoscale (onebillionth of a meter) level [2]. As applied to dentistry, this innovative approach promotes the incorporation or interaction of nanostructured materials together with the complex arrangement of organic/inorganic molecular-level constituents comprising living tooth structure, allowing for a myriad of possible preventive and therapeutic applications [2]. Owing to this progression of material development, the assignments of additional revolutionary dimensions have included the origination of the concepts of biocompatibility or bioactivity into dental science.
As a possible expansion of nanotechnology applied to dental materials: the terms biocompatible, bioactive, bioinduction, and biomimetics can be defined independently; however, have often been characterized synonymously [3]. Biocompatible is simply a term to describe a substance or material that will do no harm to existing living structures, that is non-mutagenic and noncytotoxic. The term "bioactivity" was first described in 1969 by Hench, whereby a "bioactive material is one that elicits a specific biological response at the interface of the material which results in the formation of a bond between the tissues and the material" [4]. Furthermore, the definition was refined and updated to include two categories based upon intent and procedure, originally pertaining, specifically, to bone tissue:

a) Class A: A material that elicits an intracellular and extracellular response (osteoproductive); 
b) Class B: Materials eliciting an extracellular response only (osteocontuctive) [5].

Accordingly, a bioactive material can have "the effect on, or eliciting a response from living tissue, organisms, or cells", thus contributing to the formation of a new substance or creation of a living, compatible system [3]. A bioinductive property is defined as "the capability of a material for inducing a response in a biologic system"[3]. Biomimetics is the "study of formation, structure, or function of biologically produced substances and materials and biological mechanisms and processes for the purpose of synthesizing similar products by artificial mechanisms that mimic natural substances"[3,6]. So, although these terms seem to imply different connotations, what can a dental practitioner conclude, deduce, and/or apply for everyday use? Any substance, arrived from by any process (bioactive, bioinduction, biomimetic) should exhibit attributes of being biocompatible. It appears that both a bioactive and biomimetic substance can include the process of bioinduction and that a biomimetic substance could possibly be produced through bioactive activities.

Bioactive materials and processes are probably the most applicable for endodontics and restorative dentistry based upon current uses: luting cements, pulp capping agents, root repair materials, permanent restorations, hard tissue remineralization (fluoride, calcium, and phosphate ions) and bone regeneration properties, and treatment of dentinal hypersensitivity[1,3,7-13]. In order for these materials to become biocompatibily active or retain characteristics of bioactivity; bactericidal and bacteriostatic (inhibits bacterial growth and biofilm formation) properties for the stimulation of reparative dentin formation and maintenance of pulpal vitality must be achieved and maintained [3]. Examples include fluorides for remineralization, antibacterial resins and cements (Reactimer bond ${ }^{\mathrm{TM}}$ Shofu Dental Corp., Kyoto, Japan; $\mathrm{ABF}^{\mathrm{TM}}$ Kuraray, Kurasiki, Japan), restoratives (Active ${ }^{\mathrm{TM}}$ BioACTIVE, PULPDENT Corp., Watertown, MA, USA) releasing fluorides and containing amorphous calcium phosphates [ACP], medicaments (mineral trioxide aggregate [MTA] and bioaggregate; Biodentine ${ }^{\mathrm{TM}}$, Septodont, Lancaster, PA, USA; TheraCal ${ }^{\mathrm{TM}}$, Bisco Dental Products, Schaumburg, ILL, USA; and Endosequence root repair [RRM] ${ }^{\mathrm{TM}}$, Brasseler USA, Savannah, GA), and luting cements (Ceramir Crown \& Bridge, Doxa Dental Inc., Chicago, ILL, USA) that induce healing and/or for creation of new tooth structures[1,3,7,8,10-14]. Biomimetic substances include the usage of polyvinylphosponic acid (PVPA) polyacrylic acids (PAA) as calcium phosphate matrix protein analogues for remineralization purposes $[7,15]$.

\section{Conclusion}

Although these materials are in their infancy, with long-term efficacy based on improvements of mechanical and physical properties pending, future materials will hopefully create circumstances for increased tooth-like attributes due to properties of adhesion, remineralization, and integration $[1,3,7]$.

\section{References}

1. Asthana G, Bhargava S (2014) Bioactive materials: A comprehensive review. Sch J App Med Sci 2(6E): 3231-3237.

2. Elkassas D, Arafa A (2017) The innovative applications of therapeutic nanostructures in dentistry. Nanomedicine: Nanotechnology, biology, and Medicine 13(4): 1543-1562.

3. Sonarkar S, Purba R (2015) Bioactive materials in conservative dentistry. International Journal of Contemporary Dental and Medical Reviews p. $1-4$.

4. Hench LL, Splinter RJ, Allen WC, Greenlee TK (1972) Bonding mechanisms at the interface of ceramic prosthetic materials. J Biomed Mater Res 5(6): 117-141.

5. Hench LL (1994) Bioactive ceramics: Theory and clinical applications. In: Andersson OH, Yli Urpo A (Eds.), Bioceramics, Butterworth Heinemann, Oxford, UK 7: 3-14.

6. Anusavice KJ, Shen C, Rawls HR (2013) Phillip's Science of Dental Materials. (12 ${ }^{\text {th }}$ edn), Dental Materials 21: 519.

7. Chen Liang, Shen H, Suh BI (2013) Bioactive dental restorative materilas: A review. Am J Dent 26(4): 219-227.

8. Imazato S (2009) Bio-active restorative materials with antibacterial effects: New dimension of innovation in restorative dentistry. Dental materials Journal 28(1): 11-19.

9. Loof J, Svahn F, Jarmar T, Engqvist H, Pameijer CH A (2008) comparative study of the bioactivity of three materials for dental applications. Dental Materials 24(5): 653-659.

10. Jefferies SR (2013) Bioactive and biomimetic restorative materials: A comprehensive review, Part II. Journal of Esthetic and Restorative Dentistry 26(1): 14-26.

11. Jefferies SR (2016) Bioactive dental materials: Composition, properties, and indications for a new class of restorative materials. Inside Dentistry 12(2).

12. Comisi JC (2012) Bioactive materials support proactive dental care. Cosmetic Dentistry 1: 7-13.

13. (2013) Activa $^{\mathrm{TM}}$ BioACTIVE-RESTORATIVE: BioACTIVE Products for ProACTIVE Dentistry. PULPDENT Corporation.

14. Comisi JC (2013) The Reservoir Restorative Revolution. Dental CE today. com 35(7): 126.

15. Kim YK, Gu LS, Bryan TE, Kim JR, Chen L, et al. (2010) Mineralization of reconstituted collagen using polyvinylphosphonic acid/polyacrylic acid templating matrix protein analogues in the presence of calcium, phosphate and hydroxyl ions. Biomaterials 31(25): 6618-6627. 
This work is licensed under Creative Commons Attribution 4.0 License

To Submit Your Article Click Here: Submit Article

DOI: 10.32474/MADOHC.2018.02.000132

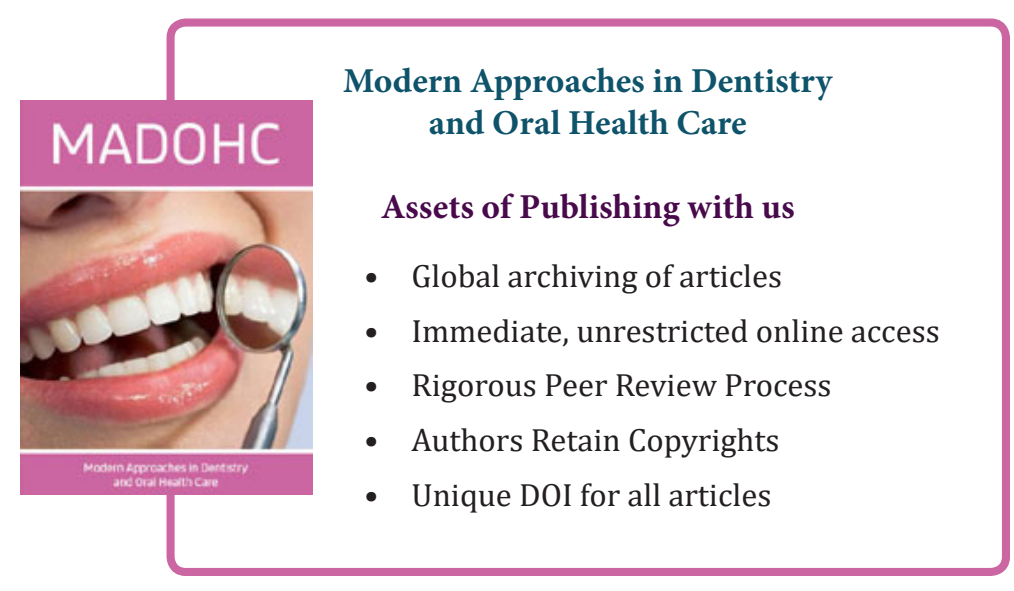

